\title{
PERFORMANCE ASSESSMENT OF A MEDIUM-SCALE TURBOPROP ENGINE DESIGNED FOR UNMANNED AERIAL VEHICLE (UAV) BASED ON EXERGETIC AND SUSTAINABILITY METRICS
}

\author{
O.Balli1,*
}

\begin{abstract}
This study presents an exergetic and sustainability analyses to assess the performance of a genuine medium scale turboprop engine (m-TPE) used on the Unmanned Aerial Vehicle (UAV). The exergy efficiency of the engine is obtained to be $17.24 \%$ whereas the exergy efficiencies of the compressor, the combustor, the gas generator turbine, the gas generator turbine mechanical shaft, the power turbine, the power turbine mechanical shaft and the exhaust duct are found to be $87.21 \%, 52.51 \%, 98.53 \%, 98.60 \%, 97.40 \%, 98.00 \%$, and $94.29 \%$, respectively. From the viewpoint of thermodynamics, the combustor is determined to be the bad factor on the engine performance among the engine components. According to overall engine analysis, the environmental effect factor, exergetic sustainability index, sustainable efficiency factor and ecological effect factor of m-TPE are found to be 4.80, 0.21, 1.21, and 5.80, respectively.
\end{abstract}

Keywords: Turboprop Engine, Unmanned Aerial Vehicle, Exergy Analysis, Sustainability Analysis

\section{INTRODUCTION}

Rapid developments and significant progress in aerospace engineering is observed in the present era. Particularly advances in unmanned aerial vehicle (UAV) developments for specific requirements and demands play a determining role. Worldwide researches and studies on UAVs, applicable for military and surveillance purposes, are driving forces of the scientific advancement [1-4]. That yields technological achievements in engine and propulsion system development and integration as well as aerial vehicle design and manufacture.

Turbine engines are widely used devices to generate required thrust for most of the aerial vehicles due to their features. Turbine engines are candidate to serve as propulsion system of UAVs as well as commercial and fighter aircrafts in spite of electromotor known with their characteristics such as light weight, durability, and low cost. Especially military applications require long endurance and flight envelope. If the weight of an armed UAV is considered in company with flight range and envelope, an electromotor is insufficient to power the UAV. For this reason, turbine engines are commonly preferred in military UAVs such as MQ-9 Reaper, RQ-4 Global Hawk, TAI ANKA, General Atomics Avenger and so on [5-11].

It is possible to access many studies on the exergetic, exergoeconomic and sustainability performance evaluations of aircraft gas generator turbine engines [11-35]. At a glance it is clearly understood from these previous texts that both first and second laws of thermodynamics should be employed together to measure the performance of the turbine engines. The first law of thermodynamics manifests the energy conversion phenomena within the evaluated turbine engine. Furthermore using governing equation set of first law is a powerful tool to measure quantity of energy inputs or outputs such as provided energy, generated shaft power, thrust and so on. The second law thermodynamics explains the limitations of the turbine engine according to well-accepted principles asserted by Carnot, Clausius, Kelvin and Planck. So, it is possible to determine design points, optimize and to evaluate improvement feasibility of a turbine engine with the aid of thermodynamics. The combined employment of first and second laws in a performance assessment has a proper name: exergy analysis [36-37].

This paper was recommended for publication in revised form by Regional Editor Yasin Karagöz

${ }^{1}$ F35 Maintenance Department, ${ }^{\text {st }}$ Air Maintenance Factory Directorate (1.HBFM), Eskisehir,, Turkey

${ }^{\star} E$-mail address: balli07balli@yahoo.com, balli.o@hvkk.tsk.tr

Orcid id: https://orcid.org/0000-0001-6465-8387

Manuscript Received 22 September 2018, Accepted 27 November 2018 
An exergetic analysis is a tool to verify the location, size and sources of thermodynamic wastefulness in any energy conversion system or process. This beneficial tool provides data that is impossible to obtain by only energy analysis.

The obtained result from exergy analysis may be employed to improve the efficiency and cost effectiveness of a system while comparing the performance of different systems [38]. In this regard, the exergy analysis of a new designed medium scale turboprop engine (m-TPE) used on the UAV is performed to evaluate the performance of the system. The main goals of the present study are (i) to assess the performance of a new designed medium-scale turboprop engine exergetically, (ii) to estimate the inefficiencies in the components of the engine, and (iii) to determine which component is improved, upgraded or replaced to increase the efficiency of the engine.

\section{ANALYZING METHODOLOGY Exergy Analysis}

Exergy analysis, combination of first and second laws of thermodynamics, shows that exergy waste is a measure of the irreversibility of a process, and that it is proportional to the increase in entropy. Exergy deals with the quality of energy and leads to the property of entropy, which is the measure of disorder in a system. Exergy enables us to determine the best performance of cycles, engines, and devices under operating conditions [39-40].

For any control volume at steady state system, exergy balance relation can be written as [41-42]:

$$
\dot{E} x_{F}=\sum \dot{E} x_{i n, t o t}=\dot{E} x_{\mathrm{Pr}}+\sum_{k=1}^{n} \dot{E} x_{D, k}+\dot{E} x_{L}
$$

where $\dot{E} x$ is the exergy rate. The subscripts $F, \operatorname{Pr}, D$ and $L$ denote the total inlet exergy as fuel exergy, the product exergy, the exergy destruction and exergy losses, respevtively.

Total waste exergy rate $\left(\dot{E} x_{W E}\right)$ is determined by:

$$
\dot{E} x_{W E}=\sum \dot{E} x_{D}+\sum \dot{E} x_{L}
$$

Total exergy rate for thermal systems that have not nuclear, magnetism, electricity and surface tension effects can be obtained by [43]:

$$
\dot{E} x_{t o t}=\dot{m}\left(\varepsilon_{p h}+\varepsilon_{k n}+\varepsilon_{p t}+\varepsilon_{c h}\right)
$$

here $\varepsilon_{p h}$ represents the specific physical exergy, $\varepsilon_{k n}$ denotes the kinetic exergy, $\varepsilon_{p t}$ symbolizes specific potential exergy, and $\varepsilon_{c h}$ stands for chemical exergy, respectively.

The specific physical exergy of air and combustion gases with constant specific heat capacity is estimated from [43-46]:

$$
\varepsilon_{p h}=c_{P(T)}\left[T-T_{o}-T_{o} \ln \left(\frac{T}{T_{o}}\right)\right]+R T_{o} \ln \left(\frac{P}{P_{o}}\right)
$$

The specific kinetic exergy of air and combustion gases is determined from [43-45]:

$$
\varepsilon_{k n}=\frac{V^{2}}{2000}
$$


Journal of Thermal Engineering, Research Article, Vol. 6, No. 5, pp. 697-711, October, 2020

The specific fuel chemical exergy is obtained from [43-45]:

$$
\varepsilon_{c h, F}=L H V \xi
$$

where $\xi$ symbolizes the exergy grade function for liquid fuels. The $\xi$ of a liquid fuel that have chemical formula as $C_{a} H_{b}$ is calculated by [30, 42, 44-45]: ,

$$
\xi \cong 1.04224+0.011925 \frac{b}{a}-\frac{0.042}{a}
$$

For JP-8 jet fuel $\left(C_{12} H_{23}\right)$, the $\xi$ is obtained to be 1.0616 .

\section{Performance Tools for Exergetic and Sustainability Analyses}

Exergetic and sustainability performance assessment metrics for aero-engine and its major components were suggested in many former studies $[13,19,22,29,33,47-50]$ and some of them are given in Table 1.

\begin{tabular}{|c|c|c|c|c|}
\hline Performance metrics & Symbol & Unit & Equations & Eqn.No. \\
\hline Exergy efficiency & $\eta$ & $(\%)$ & $\eta_{k}=\frac{\dot{E} x_{\mathrm{Pr}}}{\dot{E} x_{F}}=1-\frac{\dot{E} x_{D}}{\dot{E} x_{F}}$ & (8) \\
\hline Exergetic improvement potential & $\dot{E} x I P_{k}$ & $(\mathrm{~kW})$ & $\dot{E} x I P=(1-\eta) \dot{E} x_{D}$ & (9) \\
\hline $\begin{array}{l}\text { Relative exergetic improvement potential } \\
\text { ratio }\end{array}$ & $\alpha$ & $(\%)$ & $\alpha=\frac{\dot{E} x I P}{\sum \dot{E} x I P_{T P E}}$ & (10) \\
\hline Relative exergy destruction ratio & $\beta$ & $(\%)$ & $\beta=\frac{\dot{E} x_{D}}{\sum \dot{E} x_{D, T P E}}$ & (11) \\
\hline Relative waste exergy ratio & $\chi$ & $(\%)$ & $\chi=\frac{\dot{E} x_{W E}}{\sum \dot{E} x_{W E, T P E}}$ & (12) \\
\hline Fuel exergy waste ratio & $\delta$ & $(\%)$ & $\delta=\frac{\dot{E} x_{W E}}{\sum \dot{E} x_{F, T P E}}$ & (13) \\
\hline Productivity lack ratio & $\phi$ & $(\%)$ & $\phi=\frac{\dot{E} x_{W E}}{\sum \dot{E} x_{\mathrm{Pr}, T P E}}$ & (14) \\
\hline Environmental effect factor & $\varphi$ & $(-)$ & $\varphi=\frac{\delta}{\eta}$ & (15) \\
\hline Exergetic sustainability index & $\kappa$ & $(-)$ & $\kappa=\frac{1}{\varphi}$ & (16) \\
\hline Sustainable efficiency factor & $\lambda$ & $(-)$ & $\lambda=\frac{1}{1-\eta}$ & (17) \\
\hline Ecological effect factor & $\mu$ & $(-)$ & $\mu=\frac{\dot{E} x_{F}}{\dot{E} x_{\mathrm{Pr}}}=\frac{1}{\eta}$ & (18) \\
\hline
\end{tabular}

Table 1. Exergetic and sustainability performance metrics 


\section{SYSTEM DESCRIPTION AND ASSUMPTIONS \\ General Engine Description and Technical Data}

A turboprop engine (m-TPE) consists of a compressor (AC), a combustor (CC), a gas generator turbine (GT), a gas generator turbine mechanical shaft (GTMS), a free power turbine (PT), a power turbine mechanical shaft (PTMS), an exhaust duct (ED) and and propeller. The simplified schematic of the m-TPE is illustrated in Fig 1. In the m-TPE, the ambient air is compressed to a higher pressure by the AC (1-2). The heat addition is supplied in the $\mathrm{CC}$ to increase the temperature of the air. The fuel (3) and air (2) are mixed and burned in the combustion process which also raised the enthalpy of working fluid (2-4). The combustion gases (4-5) are expanded throughout the GT to produce the mechanical work that drives the AC via the GTMS (8-9). After that, the combustion gases (5-6) are dilated through the PT to generate the mechanical power that rotates the propeller with PTMS (10-11). Finally, the exiting combustion gases from the PT go through the ED and emits to atmosphere.

The investigated $\mathrm{m}$-TPE was developed for using on the UAV. Under the sea level condition at $\mathrm{T}_{\mathrm{o}}=288.15 \mathrm{~K}$ and $\mathrm{P}_{\mathrm{o}}=101.325 \mathrm{kPa}$, the $\mathrm{m}-\mathrm{TPE}$ has the following technical data [51]:

- $\quad$ Maximum shaft power: $1000 \mathrm{~kW}$

- Maximum residual power (kinetic energy of exhaust gases): $135 \mathrm{~kW}$

- $\quad$ Pressure ratio of compressor: 5.5

- Mass rate of inlet air: $8.66 \mathrm{~kg} / \mathrm{s}$

- Mass flow rate of JP-8 jet fuel: $0.145 \mathrm{~kg} / \mathrm{s}$.

- $\quad$ Air-fuel ratio: 59.72

- Pressure drop in the combustor: 5\%

- Gas generator turbine inlet temperature: $1058.15 \mathrm{~K}$.

- Gas generator turbine outlet temperature: $890.35 \mathrm{~K}$

- $\quad$ Pressure ratio of gas generator turbine: 2.68

- Power turbine outlet temperature: $799.50 \mathrm{~K}$

- $\quad$ Pressure ratio of power turbine: 1.8

- Exhaust outlet temperature and pressure: $797.25 \mathrm{~K}$ and $107.55 \mathrm{kPa}$

- Velocity of exhaust gases: $175.5 \mathrm{~m} / \mathrm{s}$

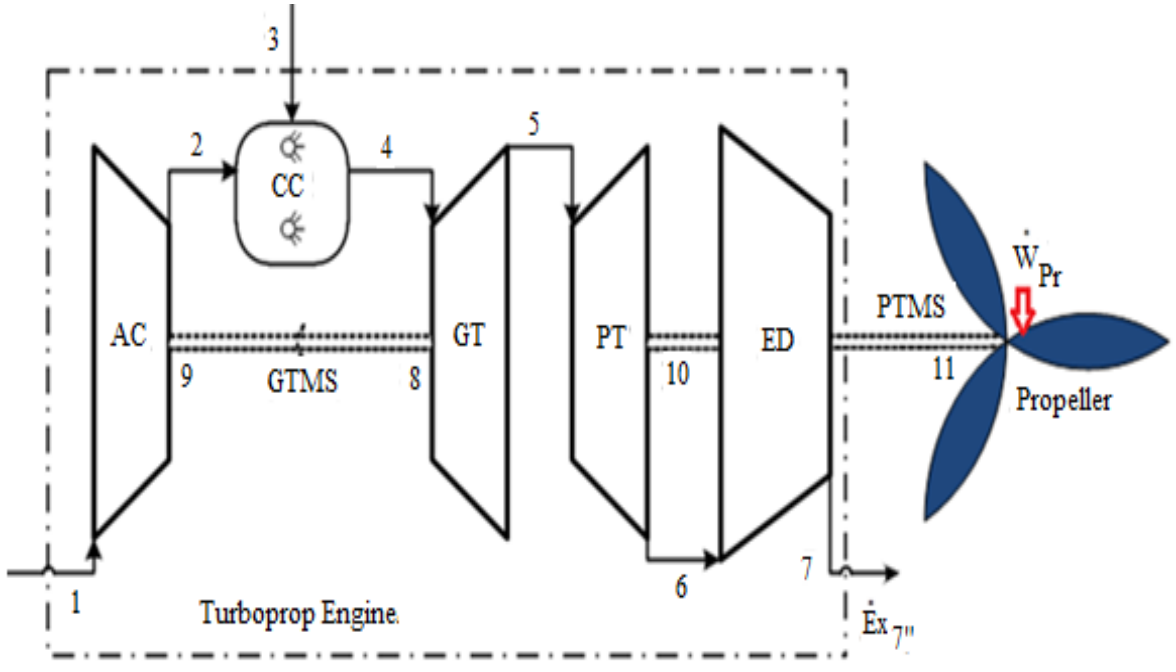

Figure 1. A simplified schematic of the investigated m-TPE

\section{Assumptions}

The flowing postulates are made are for this study:

- The m-TPE run in a steady-state and steady flow.

- The air and combustion gases were assumed as an ideal-gas mixture.

- The combustion reaction was complete. 
Journal of Thermal Engineering, Research Article, Vol. 6, No. 5, pp. 697-711, October, 2020

- The fuel inletting into combustor was the JP-8 fuel.

- The chemical formula of JP-8 was presumed $\mathrm{C}_{12} \mathrm{H}_{23}$.

- The lower heating value of JP-8 fuel was to be $42,800 \mathrm{~kJ} / \mathrm{kg}$.

- The compressor, the gas generator turbine and the power turbine were taken into consideration as adiabatic.

- The changes in the kinetic energy and exergy rates, the potential energy and exergy rates within the engine were assumed to be negligible.

- The air mass flow velocity entering the compressor was zero hence the engine test was made in a static condition at test cell.

- The cooling air mass rate was ignored.

- The environmental state was taken to be $288.15 \mathrm{~K}$ and $101.33 \mathrm{kPa}$, respectively.

\section{Specific Heat Capacity of Air and Combustion Gases}

The pressured air at compressor outlet goes into the combustor and mixes by sprayed jet fuel. The mixed air-jet fuel is ignited by high energy igniter and burning starts in the combustor. For stable burning, the air-fuel ratio must be at convenient level. The air- fuel ratio in the combustor is always higher than stoichiometric ratio for completed fuel burning and decreasing the combustion gases temperature in inlet of the gas generator turbine. The combustion reaction relation for JP-8 jet fuel is written as following:

$$
\mathrm{C}_{12} \mathrm{H}_{23}+348.7985\left(\begin{array}{l}
0.7448 \mathrm{~N}_{2}+ \\
0.2059 \mathrm{O}_{2}+ \\
0.0003 \mathrm{CO}_{2}+ \\
0.019 \mathrm{H}_{2} \mathrm{O}
\end{array}\right) \rightarrow 12.1046 \mathrm{CO}_{2}+8.1272 \mathrm{H}_{2} \mathrm{O}+0676 \mathrm{O}_{2}+270.249 \mathrm{~N}_{2}
$$

After combustion reaction, the mass compositions of combustion gases are obtained to be $5.24 \% \mathrm{CO}_{2}$, $3.21 \% \mathrm{H}_{2} \mathrm{O}, 17.03 \% \mathrm{O}_{2}$ and $74.51 \% \mathrm{~N}_{2}$. The universal gas constant ( $\left.\mathrm{R}_{\mathrm{gas}}\right)$ of the exhaust gases is obtained to be $0.29136 \mathrm{~kJ} / \mathrm{kgK}$. The specific heat capacity of exhaust gases $\left(c_{P, c g}\right)$ is calculated by [52]:

$$
c_{P, c g}(T)=0.98836+\frac{0.01138}{10^{2}} T+\frac{0.01540}{10^{5}} T^{2}-\frac{0.06695}{10^{9}} T^{3}
$$

The specific heat capacity of air is accounted by [19, 22, 30, 41, 43-45]:

$$
c_{P, a}(T)=1.04841-\left(\frac{3.83719 T}{10^{4}}\right)+\left(\frac{9.45378 T^{2}}{10^{7}}\right)-\left(\frac{5.49031 T^{3}}{10^{10}}\right)+\left(\frac{7.92981 T^{4}}{10^{14}}\right)
$$

Here $T$ is temperature in Kelvin unit.

\section{Exergy Balance Relations}

The exergy balance relations in this study are written in accordance with the F(fuel)-Pr (Product) rule [40]. The exergetic balance relations for the m-TPE and its major components are given as following;

For compressor (AC):

$$
\dot{E} x_{D, A C}=\dot{W}_{9}-\left(\dot{E} x_{2}-\dot{E} x_{1}\right)
$$


Journal of Thermal Engineering, Research Article, Vol. 6, No. 5, pp. 697-711, October, 2020

For combustor (CC):

$$
\dot{E} x_{D, C C}=\dot{E} x_{3}-\left(\dot{E} x_{4}-\dot{E} x_{2}\right)
$$

For gas generator turbine (GT):

$$
\dot{E} x_{D, G T}=\left(\dot{E} x_{4}-\dot{E} x_{5}\right)-\dot{W}_{8}
$$

For gas generator turbine mechanical shaft (GTMS):

$$
\dot{E} x_{D, G T M S}=\dot{W}_{8}-\dot{W}_{9}
$$

For power turbine (PT):

$$
\dot{E} x_{D, P T}=\left(\dot{E} x_{5}-\dot{E} x_{6}\right)-\dot{W}_{10}
$$

For power turbine mechanical shaft (PTMS):

$$
\dot{E} x_{D, P T M S}=\dot{W}_{10}-\dot{W}_{11}
$$

For exhaust duct (ED):

$$
\dot{E} x_{D, E D}=\left(\dot{E} x_{6}-\dot{E} x_{7}\right)
$$

Total exergy destruction rates can be written as:

$$
\sum \dot{E} x_{D, T P E}=\dot{E} x_{D, A C}+\dot{E} x_{D, C C}+\dot{E} x_{D, G T}+\dot{E} x_{D, G T M S}+\dot{E} x_{D, P T}+\dot{E} x_{D, P T M S}+\dot{E} x_{D, E D}
$$

On the other hand; total exergy losses rates are estimated by:

$$
\begin{gathered}
\sum \dot{E} x_{L, T P E}=\left(\dot{E} x_{1}+\dot{E} x_{3}\right)_{T P E}-\sum \dot{E} x_{\mathrm{Pr}, T P E}-\sum \dot{E} x_{D, T P E} \\
\sum \dot{E} x_{\mathrm{Pr}, T P E}=E x_{7, T P E}^{K N}+\dot{W}_{11, T P E}
\end{gathered}
$$

\section{RESULTS AND DISCUSSION}

The thermodynamic cycle data is given in Table 2 for investigated m-TPE. Using data in Table 2, the exergy rates, exergetic and sustainability performance indicators of the m-TPE and its major subcomponents are obtained and listed in Table 3 and 4. 
Journal of Thermal Engineering, Research Article, Vol. 6, No. 5, pp. 697-711, October, 2020

Table 2. The exergy rate and other thermodynamic properties of the m-TPE at maximum operation power

\begin{tabular}{|l|l|l|l|l|l|l|l|}
\hline $\begin{array}{l}\text { State } \\
\text { no. }\end{array}$ & Fluid type/work & $P(k P a)$ & $T(K)$ & $\dot{m}\left(k g s^{1}\right)$ & $c_{P}\left(k J(k g-K)^{-1}\right)$ & $\dot{E}(k W)$ & $\dot{E} x(k W)$ \\
\hline 0 & Air & 101.33 & 288.15 & 0.00 & 1.00375 & 0.00 & 0.00 \\
\hline 1 & Air & 101.33 & 288.15 & 8.66 & 1.00375 & 0.00 & 0.00 \\
\hline 2 & Air & 557.29 & 498.15 & 8.66 & 1.02887 & 1933.80 & 1686.54 \\
\hline 3 & Fuel & 250.09 & 298.15 & 0.15 & 1.94700 & 6206.00 & 6588.29 \\
\hline 4 & Combustion gases & 529.42 & 1058.15 & 8.81 & 1.12912 & 7973.32 & 5145.93 \\
\hline 5 & Combustion gases & 197.55 & 890.35 & 8.81 & 1.09174 & 6012.04 & 3155.43 \\
\hline 6 & Combustion gases & 109.75 & 799.50 & 8.81 & 1.07080 & 4991.30 & 2107.48 \\
\hline 7 & Combustion gases & 107.55 & 797.25 & 8.81 & 1.07027 & 4966.43 & 1987.16 \\
\hline 8 & Mechanical power & & & & & 1961.28 & 1961.28 \\
\hline 9 & Mechanical power & & & & & 1933.80 & 1933.80 \\
\hline 10 & Mechanical power & & & & & 1020.74 & 1020.74 \\
\hline 11 & Mechanical power & & & & & 1000.33 & 1000.33 \\
\hline 7 ”, & Residual kinetic & & & & & 135.60 & 135.60 \\
& & & & & & \\
\hline
\end{tabular}

Table 3. The exergy rate, exergy efficiency and exergetic improvement potential of the m-TPE at maximum operation power

\begin{tabular}{|l|l|l|l|l|l|l|}
\hline Components & $\begin{array}{l}\dot{E} x_{F} \\
(k W)\end{array}$ & $\begin{array}{l}\dot{E} x_{\mathrm{Pr}} \\
(k W)\end{array}$ & $\begin{array}{l}\dot{E} x_{D} \\
(k W)\end{array}$ & $\begin{array}{l}\dot{E} x_{L} \\
(k W)\end{array}$ & $\begin{array}{l}\eta \\
(\%)\end{array}$ & $\begin{array}{l}\dot{E} x I P \\
(k W)\end{array}$ \\
\hline AC & 1933.80 & 1686.54 & 247.26 & & 87.21 & 31.62 \\
\hline CC & 6588.29 & 3459.39 & 3128.90 & & 52.51 & 1485.98 \\
\hline GT & 1990.50 & 1961.28 & 29.22 & & 98.53 & 0.43 \\
\hline GTMS & 1961.28 & 1933.80 & 27.48 & & 98.60 & 0.38 \\
\hline PT & 1047.95 & 1020.74 & 27.20 & & 97.40 & 0.71 \\
\hline PTMS & 1020.74 & 1000.33 & 20.41 & & 98.00 & 0.41 \\
\hline ED & 2107.48 & 1987.16 & 120.32 & & 94.29 & 6.87 \\
\hline$\sum \dot{E} x_{D}$ & & & 3600.80 & & & \\
\hline$\sum \dot{E} x_{L}$ & & & & 1851.56 & & \\
\hline$\sum \dot{E} x I P$ & & & & & & 1526.39 \\
\hline Shaft power $\left(\dot{W}_{11}\right)$ & & 1000.33 & & & & \\
\hline Kinetic exergy $\left(\dot{E} x_{7}\right)$ & & 135.60 & & & & \\
\hline The m-TPE & 6588.29 & 1135.93 & 3600.80 & 1851.56 & 17.24 & \\
\hline
\end{tabular}

The engine produces $1135.93 \mathrm{~kW}(100.33 \mathrm{~kW}$-shaft power and $135.60 \mathrm{~kW}$ - kinetic energy rate of exhaust gases) for the maximum running mode at the sea level when it expends $6588.29 \mathrm{~kW}$-exergy rate of JP-8 fuel. The exergetic efficiency $(\eta)$ of the m-TPE is obtained to be $17.24 \%$. On the other hand, total waste exergy flow is estimated to be $5452.36 \mathrm{~kW}$. The exergy destruction rate portion of the waste exergy is calculated to be $3600.8 \mathrm{~kW}$ while the exergy losses portion is accounted to be $1851.56 \mathrm{~kW}$. The percent of product exergy rate, exergy destruction rate and exergy losses rate is illustrated in Figure 2. The percent of product exergy rate, exergy destruction rate and exergy losses rate is illustrated in Fig.2. According to the Fig. 2, 54.65\% of provided exergetic fuel rate is destructed in the end of the irreversible processes whereas $28.52 \%$ of fuel exergy rate is emitted into environment by exhaust gases as exergy losses rate of m-TPE. 


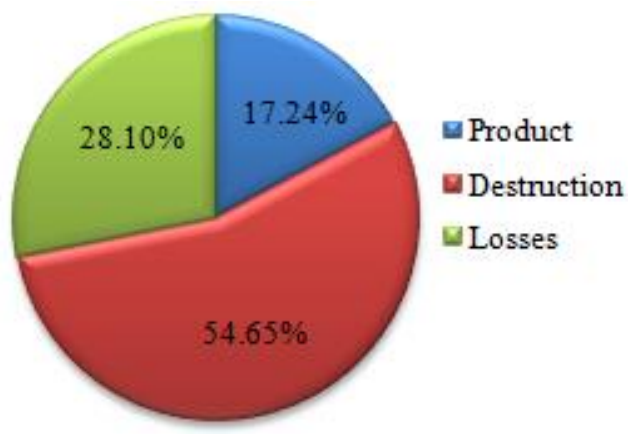

Figure 2. Breakdown of the fuel exergy rate into parts

On the other hand, the fuel exergy waste ratio $(\delta)$, productivity lack ratio $(\phi)$, environmental effect factor $(\gamma)$, exergetic sustainability index $(\kappa)$, sustainable efficiency factor $(\lambda)$ and ecological effect factor $(\mu)$ of the mTPE is obtained to be $82.76 \%, 479.99 \%, 4.80,0.21,1.21$ and 5.80 , respectively according to the sustainability analysis. In addition to Table 3 and 4, Figure 3 is plotted for a better understanding of fuel, product and destruction exergy rates of each engine component individually. As an idea to support exergy efficiency of each product, the fuel exergy rate of gas generator turbine, power turbine and turbine shafts are considerably converted into product exergy rate.

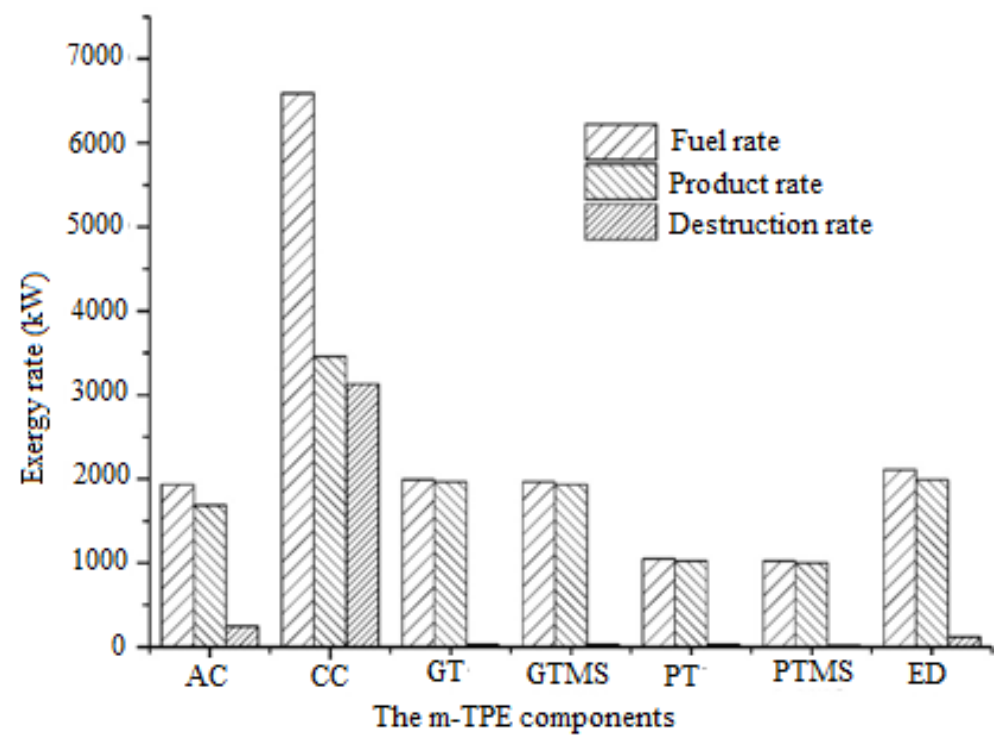

Figure 3. Exergy rate variation of engine components

On the other hand, product and destruction rates of the combustor are roughly equal and so close to each other. That implication is another indicator of the exergy efficiency variation of engine components demonstrated in Figure 4. The exergy efficiencies of the compressor, the combustor, the gas generator turbine, the gas generator turbine mechanical shaft, the power turbine, the power turbine mechanical shaft and the exhaust duct are obtained to be $87.21 \%, 52.51 \%, 98.53 \%, 98.60 \%, 97.40 \%, 98.00 \%$, and $94.29 \%$, respectively. 
Journal of Thermal Engineering, Research Article, Vol. 6, No. 5, pp. 697-711, October, 2020

Table 4. The exergetic and sustainability performance metrics of the m-TPE at maximum operation power

\begin{tabular}{|l|l|l|l|l|l|l|l|l|l|}
\hline Components & $\begin{array}{l}\alpha \\
(\%)\end{array}$ & $\begin{array}{l}\beta \\
(\%)\end{array}$ & $\begin{array}{l}\chi \\
(\%)\end{array}$ & $\begin{array}{l}\delta \\
(\%)\end{array}$ & $\begin{array}{l}\phi \\
(\%)\end{array}$ & $\begin{array}{l}\varphi \\
(-)\end{array}$ & $\begin{array}{l}\kappa \\
(-)\end{array}$ & $\begin{array}{l}\lambda \\
(-)\end{array}$ & $\begin{array}{l}\mu \\
(-)\end{array}$ \\
\hline AC & 2.07 & 6.87 & 4.535 & 3.75 & 21.77 & 0.043 & 23.238 & 7.821 & 1.147 \\
\hline CC & 97.35 & 86.89 & 57.386 & 47.49 & 275.45 & 0.904 & 1.106 & 2.106 & 1.904 \\
\hline GT & 0.03 & 0.81 & 0.536 & 0.44 & 2.57 & 0.005 & 222.138 & 68.114 & 1.015 \\
\hline GTMS & 0.03 & 0.76 & 0.504 & 0.42 & 2.42 & 0.004 & 236.432 & 71.384 & 1.014 \\
\hline PT & 0.05 & 0.76 & 0.499 & 0.41 & 2.39 & 0.004 & 235.894 & 38.522 & 1.027 \\
\hline PTMS & 0.03 & 0.57 & 0.374 & 0.31 & 1.80 & 0.003 & 316.266 & 50.000 & 1.020 \\
\hline ED & 0.45 & 3.34 & 2.207 & 1.83 & 10.59 & 0.019 & 51.629 & 17.515 & 1.061 \\
\hline$\sum \dot{E} x_{D}$ & & & 66.041 & 54.66 & 316.99 & & & & \\
\hline$\sum \dot{E} x_{L}$ & & & 33.959 & 28.10 & 163.00 & & & & \\
\hline$\sum \dot{E} x I P$ & & & & & & & & & \\
\hline The m-TPE & & & & 82.76 & 479.99 & 4.800 & 0.208 & 1.208 & 5.800 \\
\hline
\end{tabular}

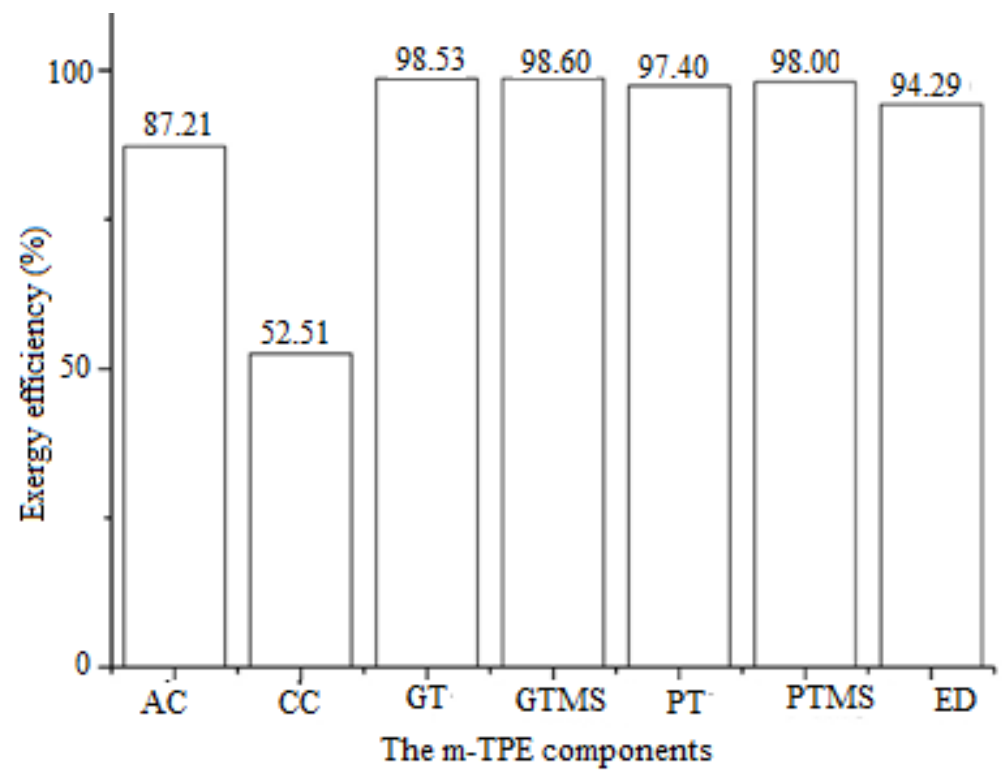

Figure 4. Exergy efficiency variation of engine components

Between the components, the highest exergy destruction occurs in the combustor with the rate of 1485.98 $\mathrm{kW}$ that is to be $86.89 \%$ of the total exergy destruction rate in the engine. According to Figures 3 and 4 , the combustor is the bad factor for engine performance from the thermodynamic viewpoint.

Figures 5 and 6 indicate exergetic performance metrics of each engine component. As shown in Figure 5, relative improvement potential ratio of the engines are found to be $6.86 \%, 86.89 \%, 0.81 \%, 0.76 \%, 0.75 \%, 0.56 \%$, and $3.34 \%$ whereas the relative exergy destruction ratio is calculated to be $2.07 \%, 97.35 \%, 0.02 \%, 0.02 \%, 0.04 \%$, $0.02 \%$, and $0.45 \%$ for the compressor, the combustor, the gas generator turbine, the gas generator turbine mechanical shaft, the power turbine, the power turbine mechanical shaft and the exhaust duct respectively. This result corroborates the assertion of combustor to be the most inefficient component with a high exergy destruction rate and improvement potential among other engine components. 


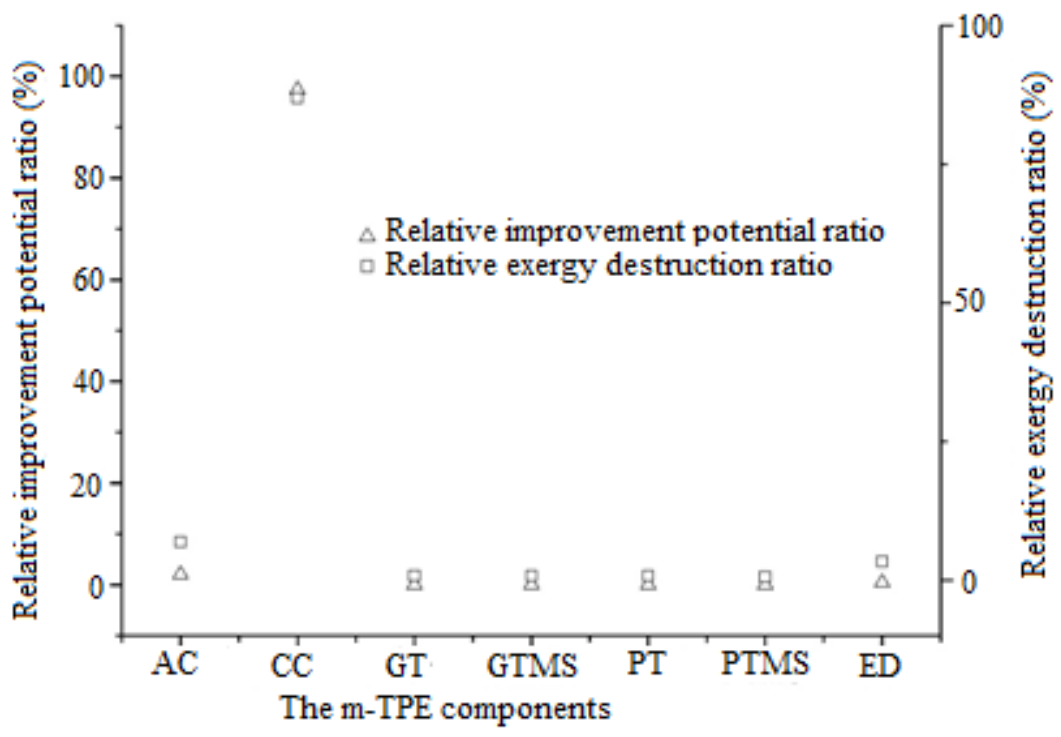

Figure 5. Relative improvement potential and relative exergy destruction ratio variation of engine components

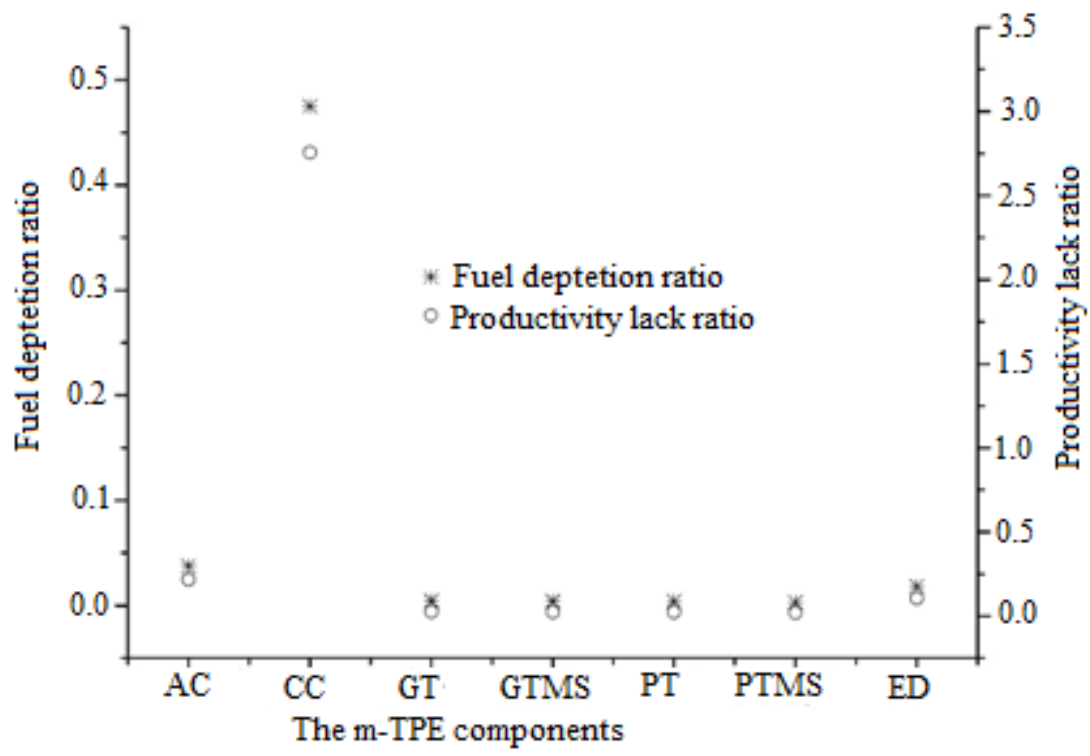

Figure 6. Fuel depletion ratio and productivity lack ratio variation of engine components

Figure 6 is another expression of Figure 3. Herein, fuel depletion ratio reveals the destructed amount of the fuel exergy rate for each component. In this manner, the combustor has the highest fuel depletion rate with value of 0.47 whereas the power turbine mechanical shaft has the lowest fuel depletion ratio. Productivity lack ratio is an indicator of destructed exergy amount compared to product exergy rate. From this point of view, fuel depletion ratio and productivity lack ratio characteristics of engine components are similar.

At the same time, the environmental and sustainability performance indicators of the m-TPE and its components are given in Table 4. The environmental effect factor and ecological effect factor of engine components are illustrated in Figure 7 while the exergetic sustainability index and sustainable efficiency factor of engine components are shown in Figure 8. Figure 7 and 8 indicate that the combustor between the engine components has the worst values of environmental effect factor, ecological effect factor, exergetic sustainability index and sustainable efficiency factor. 


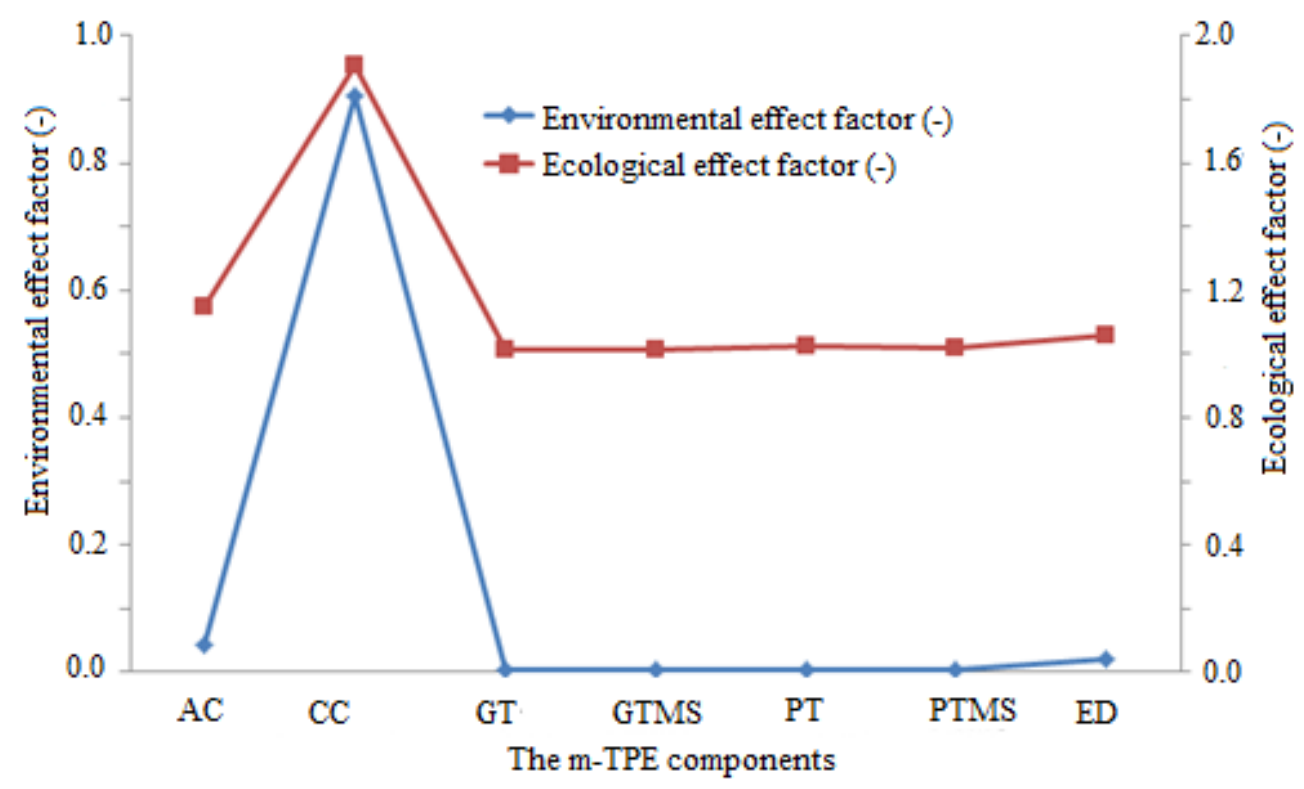

Figure 7. The environmental effect factor and ecological effect factor of engine components

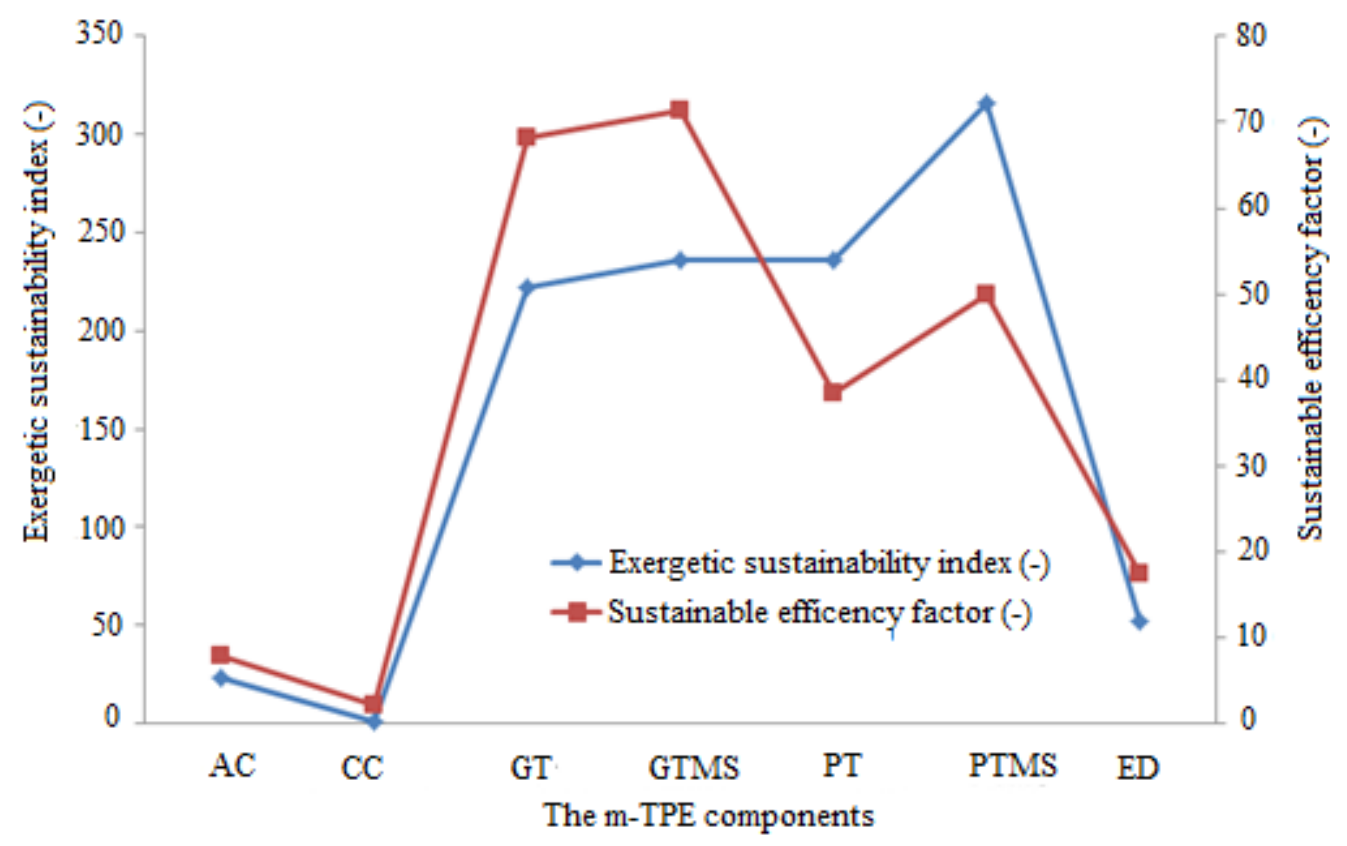

Figure 8. The exergetic sustainability index and sustainable efficiency factor of engine components.

As a result, the combustor has the maximum relative waste exergy ratio $(\chi)$, fuel exergy waste ratio $(\delta)$, productivity lack ratio $(\phi)$, environmental effect factor $(\varphi)$ and ecological effect factor $(\mu)$ with $57.39 \%, 47.49 \%$, $275.45 \%, 0.90$ and 1.90 while it has the minimum exergetic sustainability index $(\kappa=1.11)$ and sustainable efficiency factor $(\lambda=2.11)$.

The results of this study clearly point out that the combustor is the bad component for m-TPE's performance from the thermodynamic viewpoint. The combustor, in which the combustion process occurred, has the lowest exergy efficiency value, and the highest values of the other thermodynamic parameters due to the combustion 
wastefulness. Fuel burning is a very complex process and it is largely thermodynamically irreversible process. To rise up and improve the exergetic and sustainability performance of the m-TPE, the designer must focus on the combustor component to improve or develop its properties thermodynamically.

\section{CONCLUSION}

This study presents an exergy based analysis to assess the exergetic and sustainability characteristics of a genuine design medium scale turboprop engine (m-TPE) developed for UAVs. The main noteworthy outcomes of this study are given as follows:

- The exergetic efficiency value $(\eta)$ of the $\mathrm{m}$-TPE is obtained to be $17.24 \%$ while the fuel exergy waste ratio $(\delta)$ is computed to be $82.76 \%$. For increasing the exergy efficiency of the engine, the exergy waste ratio should be decreased. On the other hand, the exergy destruction rate of the combustion chamber has to be minimized in order to reduce the waste exergy rate of engine.

- The productivity lack ratio $(\phi)$ is estimated to be $479.99 \%$. Higher value of productivity lack ratio shows that the engine either generates low product rate or has higher waste exergy rate.

- The environmental effect factor $(\gamma)$ and ecological effect factor $(\mu)$ indicate that how engine running affects the environment and ecology of the world. Because higher values are the bad effect factor for environment and ecology, the low values are desired. The environmental effect factor $(\gamma)$ and ecological effect factor $(\mu)$ are calculated to be 4.80 and 5.80 for the investigated engine.

- The exergetic sustainability indexand sustainable efficiency factor $(\lambda)$ of the m-TPE are estimated to be 0.21 and 1.21 , respectively.

- Between engine major components, the combustor has the bad exergetic and sustainability metrics and it decreases the exergetic and sustainability performances from the thermodynamic viewpoint

- The results of this study indicate that the designer must concentrate on the combustor component to become better or advance its thermodynamic attributes.

\section{NOMENCLATURE}

$\begin{array}{ll}\text { AC } & \text { Air compressor } \\ c_{P} & \text { Specific heat at constant pressure, } \mathrm{kJ} / \mathrm{kgK} \\ \mathrm{CC} & \text { Combustion chamber } \\ \mathrm{E} & \text { Energy, } \mathrm{kW} \\ \mathrm{ED} & \text { Exhaust duct } \\ \dot{E} x & \text { Exergt rate, } \mathrm{kW} \\ \dot{E} x I P & \text { Exergetic improvement potantial rate, } \mathrm{kW} \\ \text { GT } & \text { Gas turbine } \\ \text { GTMS } & \text { Gas turbine mechanical shaft } \\ \mathrm{m}-\mathrm{TPE} & \text { Medium scale turboprop engine } \\ \text { LHV } & \text { Lover heating value, } \mathrm{kJ} / \mathrm{kg} \\ \mathrm{P} & \text { Pressure, } \mathrm{kPa} \\ \mathrm{PT} & \text { Power turbine } \\ \mathrm{PTMS} & \text { Power turbine mechanical shaft } \\ \mathrm{R} & \text { Relative gas constant, } \mathrm{kJ} / \mathrm{kgK} \\ \mathrm{T} & \text { Temperature, K } \\ \mathrm{UAV} & \text { Unmanned aerial vehicle } \\ \text { V } & \text { Velocity, m/s } \\ \text { W } & \text { Work rate, } \mathrm{kW}\end{array}$




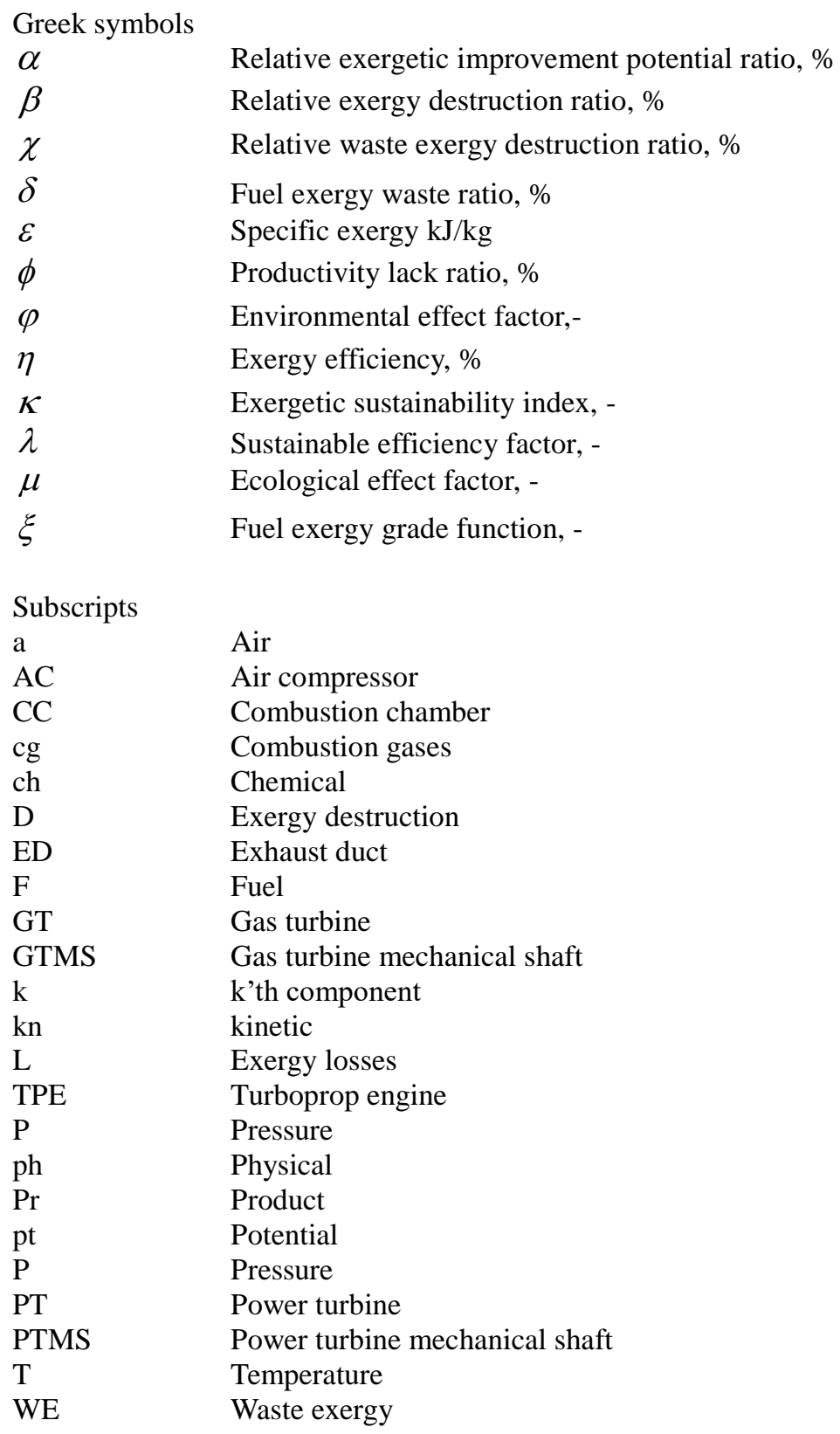

\section{REFERENCES}

[1] DeGarmo M., Nelson G.M. Prospective unmanned aerial vehicle operations in the future national airspace system. In Proceedings of AIAA 4th Aviation Technology, Integration and Operations (ATIO) Forum, 2004; 20 23.

[2] Gohardani A. A synergistic glance at the prospects of distributed propulsion technology and the electric aircraft concept for future unmanned air vehicles and commercial/military aviation. Progress in Aerospace Sciences, $2013 ; 5: 25-70$

[3] Korchenko A., Illyas O. The Generalized Classification of Unmanned Air Vehicles. In Procedings of IEEE 2nd International Conference "Actual Problems of Unmanned Air Vehicles Developments". Kyiv, Ukraine. http://ieeexplore.ieee.org/xpl/mostRecentIssue.jsp?punumber=6700567/;2013 [Accessed 2013]

[4] Gupta S.G., Ghonge M.M., Jawandhiya P.M. Review of unmanned aircraft system (UAS). International journal of advanced research in computer engineering and technology (IJARCET), 2013; 2(4):1646-1658. ISSN: 22781323. 
[5] Goraj Z., Frydrychewicz A., Świtkiewicz R., Hernik B., Gadomski J., Goetzendorf-Grabowski T., Figat M., Suchodolski St., Chajec, W. High altitude long endurance unmanned aerial vehicle of a new generation-a design challenge for a low cost, reliable and high performance aircraft. Technical Sciences. 2004; 52(3):173-194.

[6] Dinc A. Sizing ofa Turboprop Unmanned Air Vehicle and Its Propulsion System. Journal of Thermal Science and Technology. 2015; 35(2): 53-62.

[7] Dinc A. Optimization of a turboprop UAV for maximum loiter and specific power using genetic algorithm. International Journal of Turbo and Jet Engines, 2017; 33(3): 265-273.

[8] Dinc A. Optimization of turboprop ESFC and NOx emissions for UAV sizing. Aircraft Engineering and Aerospace Technology. 2017; 89(3): 375-383.

[9] TAI (Turkish Aerospace Industry, Inc.). ANKA Multi-Role ISR. https://www.tai.com.tr/en/project/ankamedium-altitude-long-endurance-uav-system/; 2017, [Accessed 04 August 2017].

[10] Predator B RPA. General Atomics Aeronautical Systems Inc.http://www.ga-asi.com/predator-b/;2017, [Accessed 04 August 2017].

[11] Predator C Avenger RPA. General Atomics Aeronautical Systems Inc. http://www.ga-asi.com/predator-cavenger./; 2017, [Accessed 04 August 2017].

[12] Liu F., Sirignano W.A. Turbojet and turbofan engine performance increases through turbine burners. Jet Propulsion Power, 2001; 17(3): 695-705.

[13] Balli O., Aras H., Aras N., Hepbasli A. Exergetic and exergoeconomic analysis of an Aircraft Jet Engine (AJE). International Journal of Exergy. 2008; 5(5/6): 567-581.

[14] Turgut E.T., Karakoc T.H., Hepbasli A. Exergoeconomic analysis of an aircraft turbofan engine. International Journal of Exergy. 2009; 6(3): 277-294.

[15] Tona C., Raviolo P.A., Pellegrini L.F., Oliveria J.S. Exergy and thermodynamic analysis of a turbofan engine during a typicalcommercial flight. Energy. 2010; 35(2): 952-959.

[16] Turan O. Exergetic effects of some design parameters on the small turbojet engine for unmanned air vehicle applications. Energy. 2012; 46(1): 51-61.

[17] Aydin H., Turan O., Karakoc T.H., Midilli A. Component-based exergetic measures of the an experimental turboprop/turboshaft engine for propeller aircrafts and helicopters. International Jornal of Exergy. 2012; 11(3): 322-348.

[18] Aydin H., Turan, O., Midilli, A., Karakoc T.H. Exergetic and exergoeconomic analysis of a turboprop engine: A case study for CT7-9C. International Journal of Exergy. 2012; 11(1): 69-82.

[19] Balli, O., Hepbasli A. Energetic and exergetic analyses of T-56 Turboprop engine. Energy Conversion and Management. 2013; 73:106-120.

[20] Hassan, H.Z. Evaluation of the local exergy destruction in the intake and fan of a turbofan engine. Energy. 2013; 63: 245-251.

[21] Ehyaei M., Anjiridezfuli A., Rosen, M. Exergetic analysis of an aircraft turbojet engine with an afterburner. Thermal Science. 2013;17(4): 1181-1194.

[22] Balli O. Afterburning effect on the energetic and exergetic performance ofan experimental turbojet engine (TJE) with afterburner. International Journal of Exergy. 2014; 14(2): 205-236.

[23] Abu Talib A., Gires E., Ahmad, M. Performance evaluation of a small-scale turbojet engine running on Palm Oil Biodiesel blends. Journal of Fuels. ID 946485, 9 pages, http://dx.doi.org/10.1155/2014/946485/; 2014; [Accessed 2014].

[24] Turan O., Aydin H., Karakoc T.H., Midilli A. Some exergetic measures of a JT8D turbofan engine. Journal of Automobile Control Engineering. 2014; 2: 110-114.

[25] Tai V.C., See P.C., Mares C. Optimisation of energy and exergy of turbofan engines using genetic algorithms. International Journal of Sustainable Aviation. 2014; 1: 25-42.

[26] Baklacioglu T., Turan O., Aydin H. Dynamic modeling of exergy efficiency of turboprop engine components using hybrid genetic algorithm-artificial neural networks. Energy. 2015; 86: 709-721.

[27] Lokesh K., Sethi V., Nikolaidis T., Goodger E., Nalianda D. Life cycle greenhouse gas analysis of biojet fuels with a technical investigation into their impact on jet engine performance. Biomass and Bioenergy. 2015; 77: 26-44.

[28] Sohret Y., Dinc A., Karakoc T.H. Exergy analysis of a turbofan engine for an unmanned aerial vehicle during a surveillance mission. Energy. 2015; 93: 716-729.

[29] Sohret Y., Sogut M., Karakoc T.H., Turan O. Customized application of exergy analysis method to PW120A turboprop engine for performance evaluation. International Journal of Exergy. 2016; 20(1): 48-65.

[30] Sohret Y. Exergo-sustainability analysis and ecological function of a simple gas turbine aero-engine. Journal of Thermal Engineering. 2018; 4(4): 2083-2093. 
[31] Coban K., Colpan C.O., Karakoc T.H. Energy and exergy analysis of an helicopter engine. Journal of Sustainable Aviation Researches. 2016; 1(1): 27-39.

[32] Coban K., Sohret Y., Colpan C.O., Karakoc, T.H. Exergetic and exergoeconomic assessment of a small-scale turbojet fuelled with biodiesel. Energy. 2017; 140: 1358-1367.

[33] Ekici S., Sohret Y., Coban K., Altuntas O., Karakoc, T.H. Performance Evaluation of an Experimental Turbojet Engine. International Journal of Turbo\&Jet Engines. http://dx.doi.org/10.1515/tjj-2016-0016/;2016 [Accessed 2016].

[34] Yucer C.T. Exergetic sustainability assessment of a gas generator turbine jet engine at part loads. Anadolu University Journal of Science and Technology A- Applied Sciences and Engineering. 2017; 18(5): 1018-1030.

[35] Yalcin E.Thrust Performance evaluation of a turbofan engine based on exergetic approach and thrust management in aircraft. International Journal of Turbo\& Jet Engines. http://dx.doi.org/10.1515/tjj-20150065/;2017 [Accessed 2017].

[36] Bejan A., Siems D. The need for exergy analysis and thermodynamic optimization in aircraft development. Exergy, An International Journal. 2001; 1(1): 14-24.

[37] Riggins D., Taylor T., Moorhouse D. Methodology for Performance Analysis of Aerospace Vehicles Using the Laws of Thermodynamics. Journal Of Aircraft. 2006; 43(4): 953-963.

[38] Bejan A., Mamut E. Thermodynamic optimization of complex energy systems. Dordrecht: Kluwer Academic Publishers. 1999.

[39] Jawad H., Jaber M., Bonney M., Rosen M. Deriving an exergetic economic production quantity model for better sustainability. Applied Mathematical Modelling. 2016; 40(11-12): 6026-6039.

[40] Koten H., Unal F., Temir G. Energy, exergy and exergoeconomic analysis of solar aaisted vertical ground source heat pump system for heating season. Journal of Mechanical Science and Technology. 2018; 32(8): 150-156.

[41] Bejan A., Tsatsaronis G., Moran M. Thermal design and optimization. New York, N.Y: John Wiley. 1996.

[42] Balli O. Advanced Exergy Analysis of a Turbofan Engine (TFE): Splitting Exergy Destruction into Unavoidable/Avoidable and Endogenous/Exogenous. International Journal Of Turbo\&Jet Engines. http://dx.doi.org/10.1515/tjj-2016-0074. 2017, [Accessed 2017].

[43] Dincer I., Rosen M.A. Exergy: energy, environment and sustainable development. Elsevier. 2007.

[44] Balli O. Advanced exergy analyses of an aircraft turboprop engine (TPE). Energy. 2017; 124: 599-612.

[45] Balli O. Advanced exergy analyses to evaluate the performance of a military aircraft turbojet engine (TJE) with afterburner system: Splitting exergy destruction into unavoidable/avoidable and endogenous/exogenous. Applied Thermal Engineering. 2017; 111: 152-169.

[46] Vafaei A. Aliehyaei M.A. Optimization of micro gas turbine by economic, exergy and environment analysis using genetic, bee colonoy and searching algorithms. Journal of Thermal Engineering, 2020; 6(1):117-140.

[47] Balli O. Exergy modeling for evaluating sustainability level of a high by-pass turbofan engine used on commercial aircrafts. Applied Thermal Engineering. 2017; 123:138-155.

[48] Aydin H., Turan O., Karakoc T.H., Midilli A. Exergo-sustainability indicators of a turboprop aircraft for the phases of a flight. Energy. 2013; 58:550-560.

[49] Balli O., Hepbasli A. Exergetic, exergoeconomic, sustainability and environmental damage cost analyses of T56 turboprop engine. Energy. 2014; 64: 582-600.

[50] Balli O. Exergetic, exergoeconomic, sustainability and environmental damage cost analyses of J85 turbojet engine with afterburner. International Journal of Turbo\&Jet Engines. http://dx.doi.org/10.1515/tjj-2017-0019/,. 2017, [Accessed 2017].

[51] 1.HBFM. 1'st Air Maintenance Factories Directorate. Turbojet and Turboprop Project Document for UAV. 2017.

[52] Cengel Y.A., Boles, M.A. Thermodynamics: An Engineering Approach. $8^{\text {th }}$ Edition, McGraw-Hill Education, 2 Penn Plaza, NY10121. 2015. 